\title{
Neuromyelitis optica with brain stem involvement in a middle-aged Ethiopian woman: a case report and review of literature
}

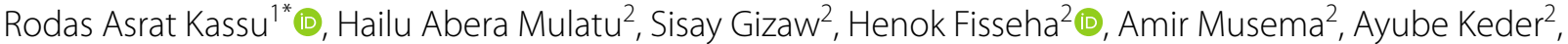
Semere Negash ${ }^{3}$, Fithanegest Tefera ${ }^{4}$, Adugna Lissanwerk ${ }^{5}$ and Lemlem Tamrat ${ }^{5}$

\begin{abstract}
Introduction: Neuromyelitis optica is a demyelinating disease of the central nervous system that predominantly affects the optic nerves and spinal cord. In neuromyelitis optica, white blood cells and antibodies primarily attack the optic nerves and the spinal cord, but may also attack the brain. Brainstem manifestation has been described recently. So far, neuromyelitis optica is very rare in Ethiopia and there were only two case reports, but this is the first case report of neuromyelitis optica with brainstem involvement.
\end{abstract}

Case presentation: A 47-year-old Addis Ababa woman presented to Saint Paul's Hospital Millennium Medical College with a history of visual loss of 7 years and bilateral lower limb weakness of 4 days duration. She had bilateral oculomotor nerve palsy. Her past medical history showed systemic hypertension for 18 years and dyslipidemia for 1 year. The objective evaluation of the patient revealed right optic nerve atrophy suggesting optic neuritis and flaccid paraplegia with sensory level at the fourth thoracic vertebra. Diagnostic work-up using electromyography and spinal magnetic resonance imaging revealed demyelinating anterior visual pathway dysfunction and signs of extensive cervicothoracic transverse myelitis from the third cervical to lower thoracic vertebrae, respectively. Then a diagnosis of neuromyelitis optica was established. After treatment with high-dose systemic steroid followed by azathioprine, the patient was stable for several months with significant improvement of vision and lower-extremity weakness with no relapse of symptoms.

Conclusion: The case described here is a rare inflammatory demyelinating disorder of the central nervous system occurring in East Africa. It reminds clinicians to suspect neuromyelitis optica in a patient who presented with unexplained recurrent optic neuritis to make a timely diagnosis and prevention of permanent neuronal damage. Neuromyelitis optica can also be associated with oculomotor nerve involvement.

Keywords: Ethiopia, Neuromyelitis optica, Optic neuritis, Transverse myelitis, Oculomotor, Brainstem, Case report

\section{Introduction}

Neuromyelitis optica (NMO) or Devic's syndrome is an autoimmune disease of the central nervous system (CNS) predominantly affecting the optic nerve and spinal

\footnotetext{
*Correspondence: asratrodas@yahoo.com; rodasasrat123@gmail.com ${ }^{1}$ Department of Neuro-surgery, St. Paul's Hospital Millennium Medical College, Addis Ababa, Ethiopia
}

Full list of author information is available at the end of the article cord [1]. The diagnosis of NMO requires the presence of optic neuritis, myelitis, spinal cord lesions involving three or more segments by magnetic resonance imaging (MRI), brain MRI not meeting the criteria of multiple sclerosis, and/or seropositive aquaporin- 4 antibodies (AQP4-Abs) [2]. The discovery of NMO immunoglobulin $\mathrm{G}$ (IgG), directed against aquaporin-4 (AQP4), has changed the clinical definition of NMO and is important in the diagnostic criteria of the disease $[1,2]$. However, original author(s) and the source, provide a link to the Creative Commons licence, and indicate if changes were made. The images or other third party material in this article are included in the article's Creative Commons licence, unless indicated otherwise in a credit line to the material. If material is not included in the article's Creative Commons licence and your intended use is not permitted by statutory regulation or exceeds the permitted use, you will need to obtain permission directly from the copyright holder. To view a copy of this licence, visit http://creativecommons.org/licenses/by/4.0/. The Creative Commons Public Domain Dedication waiver (http://creativeco mmons.org/publicdomain/zero/1.0/) applies to the data made available in this article, unless otherwise stated in a credit line to the data. 
in resource-limited settings, AQP4-Ab test is lacking and the diagnosis solely relies on the other clinical criteria. As far as the current literature, this is the third case of NMO reported from Ethiopia. It is also rarely reported from Sub-Saharan Africa. The low index of suspicion of such disease in our setup, together with diagnostic challenges, often leads to delay or misdiagnosis and worse clinical outcomes in patients that could have benefited from early treatment. We believe that the insights presented here might be useful to many other resource-limited settings.

\section{Case presentation}

\section{Patient information}

A 47-year-old woman from Addis Ababa presented to Saint Paul's Hospital Millennium Medical College (SPHMMC) medical outpatient clinic in January 2020 with a compliant of bilateral lower limb weakness of 4 days duration. She gave history of significant reduction of vision in both of her eyes before 7 years for which she visited an ophthalmologist. At that time, optic neuritis was considered, and she was given systemic prednisolone for about 2 months after which her vision improved, but the patient was lost from follow-up. Four months ago, she developed complete loss of vision of both eyes for which she visited SPHMMC ophthalmology department when recurrent optic neuritis was again considered and restarted on systemic prednisolone. With subsequent follow-ups, her vision and oculomotor palsy in her left eye improved after 2 months of prednisolone therapy. Seven weeks later, she experienced right lower limb weakness followed by left lower limb weakness within 1 day and became bedridden. She also experienced radicular back pain, urinary retention, and constipation. She had no upper limb paresthesia or weakness. She had history of hypertension of 18 years and dyslipidemia of 1-year duration. For these, she was taking amlodipine, hydrochlorothiazide, alpha-methyldopa, and atorvastatin regularly. She had no history of joint pain or skin rash. She had no history of gastrointestinal surgery or chronic diarrhea. She reported no history of recent vaccinations or diabetes mellitus. She used to work as a janitor for a wine factory until 7 years ago when she lost her job because of her vision. She has two children (one male and one female).

\section{Clinical finding}

She was conscious and alert. Her ophthalmic evaluation revealed vision of no light perception in both of her eyes. Intraocular pressure was 16 and $14 \mathrm{mmHg}$ in her right and left eye, respectively. Slit lamp examination showed afferent pupillary defect and optic nerve atrophy in the right eye and sluggishly reactive pupil but relatively normal optic nerve appearance on the left eye. She had also bilateral oculomotor nerve palsy. Several weeks later, additional systemic findings were observed including bilateral lower limb weakness with muscle power of grade 0 on the Medical Research Council (MRC) scale, with depressed reflexes at the knees and ankles. In addition, the plantar reflexes were equivocal bilaterally. She had symmetrical sensory deficit below T4 to fine touch and pressure. Coordination test was normal.

\section{Timeline}

\begin{tabular}{|c|c|}
\hline Case-previous history & $\begin{array}{l}\text { A } 47 \text {-year-old female patient who } \\
\text { was relatively healthy } 7 \text { years back } \\
\text { presented with reduced vision } \\
\text { on both eyes that progressed to } \\
\text { complete vision loss in her right eye } \\
\text { Her left eye vision showed some } \\
\text { improvement following steroid } \\
\text { therapy }\end{array}$ \\
\hline Recent complaint (2/3/19-4/6/19) & $\begin{array}{l}\text { Currently presented with } 4 \text { days } \\
\text { history of bilateral lower extremity } \\
\text { weakness } \\
\text { Initially had paresthesia of lower } \\
\text { extremities later lost sensation } \\
\text { below her nipple line } \\
\text { Inability to urinate and pass stool of } \\
\text { the same duration }\end{array}$ \\
\hline Physical examination & $\begin{array}{l}\text { Symmetrical muscle bulk, no } \\
\text { fasciculation } \\
\text { Power } 0 / 5 \text { in bilateral lower extrem- } \\
\text { ity and } 5 / 5 \text { in both upper extremi- } \\
\text { ties } \\
\text { Tone is hypotonic in both lower } \\
\text { extremities and normotonic in both } \\
\text { upper extremities } \\
\text { Reflex is } 1 / 4 \text { in both ankle and knee, } \\
\text { bilaterally sensory level is T4 } \\
\text { Finger-to-nose test-normal } \\
\text { Rapid alternating movement- } \\
\text { intact }\end{array}$ \\
\hline Investigation & $\begin{array}{l}\mathrm{CBC}-\mathrm{WBC}-11500(\mathrm{n} 78,117) \\
\mathrm{HGB}=16.8 \mathrm{~g} / 49.8,16.2 / 39.4 \\
\mathrm{MCV}=86.8, \mathrm{MCH}=29.3 \\
\mathrm{PLT}=315,000 \\
\mathrm{SGOT}=33, \mathrm{SGPT}=26, \mathrm{ALP}=117 \\
\mathrm{~T}-\mathrm{BIL}=0.6, \mathrm{D}-\mathrm{BIL}=0.2 \\
\mathrm{Cr}=0.6, \mathrm{BUN}=23, \mathrm{Na}=130 \\
\mathrm{~K}=3.6, \mathrm{CL}=108 \\
\text { Hepatic viral markers negative } \\
\mathrm{ESR}=25 \\
\text { ANA negative, VDRL negative, } \\
\mathrm{RF} \text { negative } \\
\mathrm{CSF} \text { analysis-no cell, glu- } \\
\text { cose }=82.4, \text { protein }=24.8\end{array}$ \\
\hline
\end{tabular}




\begin{tabular}{ll}
\hline Imaging & Brain MRI (taken 7 years back) nor- \\
& mal, brain MRI (taken 4 months \\
& back) \\
& Few punctate T2/FLAIR hyperin- \\
& tense lesion within deep white mat- \\
& ter of frontal and parietal lobe. Left \\
& temporoparietal volume loss \\
& Recent spinal MRI: expansile long \\
& segment T1 hypointense, T2 and \\
& STIR heterogeneously hyperintense \\
& lesion extending from C3 to lower \\
& thoracic vertebra \\
& No contrast enhancement
\end{tabular}

$H x$ History, $C B C$ complete blood count, WBC white blood cell, HGB hemoglobin, $M C V$ mean corpuscular volume, $M C H$ mean corpuscular hemoglobin, $P L T$ platelet, SGOT serum glutamic oxaloacetic transaminase, SGPT serum glutamic pyruvic transaminase, $A L P$ alkaline phosphatase, $T-B I L$ total bilirubin, $D-B I L$ direct bilirubin, $\mathrm{Cr}$ creatinine, $\mathrm{BUN}$ Blood urea nitrogen, $\mathrm{Na}$ sodium, $\mathrm{K}$ potassium, $\mathrm{Cl}$ chloride, ESR erythrocyte sedimentation rate, ANA antinuclear antibody, VDRL venereal disease research laboratory, $R F$ rheumatoid factor, STIR short tau inversion recovery, CSF cerebrospinal fluid, MRI Magnetic resonance imaging, FLAIR fluid-attenuated inversion recoveryDiagnostic assessment

Her blood work-up showed normal complete blood count, liver and renal function tests, fasting blood sugar, and serum electrolytes. Echocardiography showed mild concentric left ventricular hypertrophy. Serologic tests for human immunodeficiency virus (HIV) and syphilis were negative. Cerebrospinal fluid (CSF) analysis showed clear and colorless appearance, and normal blood glucose level $(82.4 \mathrm{mg} / \mathrm{dl})$. However, the CSF protein content was elevated at $24.8 \mathrm{mg} / \mathrm{dl}$, while the WBC count in the CSF was less than 5 cells/ $\mu$ l. Gram staining on her CSF was negative. The MRI of her cervicothoracic spine revealed expansible long segment T1 hypointense, T2 and short T1 inversion recovery (STIR) heterogeneously hyperintense lesion extending from C3 to T12 with no contrast enhancement (Fig. 1), suggesting probable myelitis or demyelination. There was no cord compressive lesion. Her brain MRI showed prominent sulci and cortical volume loss at the left parietotemporal lobe, and few punctuate T2/fluid-attenuated inversion recovery (FLAIR) hyperintense lesions within the deep white matter of the frontal and parietal lobes suggestive of nonspecific white matter lesion. Pattern reversal visual evoked potential (PRVEP) with electromyography revealed prolonged bilateral P100 latency (> $100 \mathrm{~ms}$ ), more on the right side, suggesting bilateral (severe on the right side) anterior visual pathway dysfunction of demyelinating pathophysiology (Fig. 2). As a result, a diagnosis of neuromyelitis optica was made based on the diagnostic criteria without the NMO-IgG-antibody assays [2].

\section{Therapeutic intervention}

The patient was started on intravenous methylprednisolone $1 \mathrm{~g}$ per day for 5 days followed by prednisolone $60 \mathrm{mg}$ daily and subsequently discharged with azathioprine $75 \mathrm{mg}$ daily. On discharge, she had left eye vision improvement.

\section{Follow up and outcome}

On her follow-up, prednisolone was tapered and patient was discharged on azathioprine $75 \mathrm{mg}$ daily. One year after discharge from the hospital, prednisolone was tapered to $7.5 \mathrm{mg}$ daily and azathioprine reduced to $50 \mathrm{mg}$ daily. Her vision in the right eye does not have light perception, but her left eye was $6 / 24$. She showed complete recovery from oculomotor nerve palsy on her left eye. The lower limb weakness improved with power 3/5 on MRC scale. Additionally, there was resolution of urinary retention and sensory loss. Her recent visual evoked potential showed complete improvement of her left eye vision when compared with her previous visual evoked potential; however, her right anterior visual pathway dysfunction is still present.

\section{Discussion}

Neuromyelitis optica is a severe immune-mediated inflammatory demyelinating disease of unknown etiology that predominantly affects the optic nerves and spinal cord [1]. The incidence of NMO in several studies ranged from 0.053 to 0.40 per 100,000 population, while the prevalence ranged from 0.52 to 4.4 per 100,000 population. The incidence is ten times higher in women than in men. Additionally, it is higher among Africans, Asians, and Latin Americans but is also common in Caucasians [2].

NMO is different from the classic relapsing-remitting multiple sclerosis (MS) with respect to pathogenesis, biomarkers, imaging features, and response to treatment. The target of the NMO antibody is aquaporin-4 (AQP4), a transmembrane protein that facilitates water transport in the CNS. AQP4 is highly expressed in the optic nerves, hypothalamus, brainstem, periventricular white matter, and gray matter of the spinal cord. However, only $70 \%$ of patients with NMO have positive AQP4 antibody. The remaining $30 \%$ do not express the antibody [3]. In our patient, AQP4 antibody test was not performed because it was lacking in the country at the time of diagnosis.

The main clinical features of the disorder are optic neuritis and extensive transverse myelitis. These two clinical events can occur simultaneously or separated by many years. Patients with optic neuritis can present with unilateral or bilateral eye pain and decreased vision that can rapidly progress to complete visual loss. It can occur before or after an attack of myelitis. On the other hand, patients with an attack of transverse myelitis may present with radicular back pain, symmetrical paraparesis or quadriparesis, bladder dysfunction, and sensory 


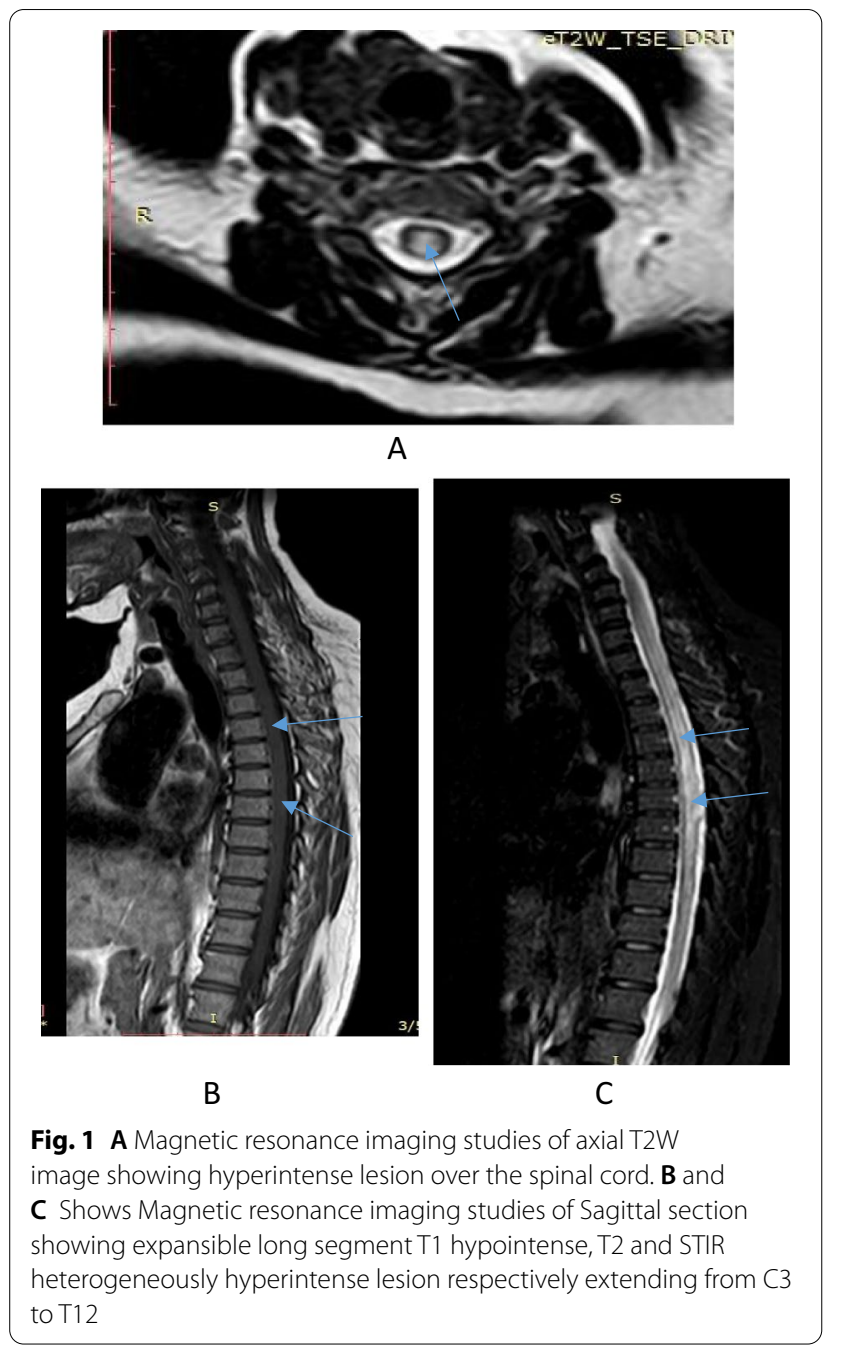

loss below the level of the spinal cord lesion. Less commonly, patients with brain involvement may experience intractable vomiting, hiccups, excessive daytime somnolence, reversible posterior leukoencephalopathy syndrome, neuroendocrine disorders, and (in children) seizures. One-third to half of patients with NMO may develop associated other autoimmune diseases such as systemic lupus erythematosus, Sjögren's syndrome, autoimmune thyroiditis, myasthenia gravis, pernicious anemia, immune thrombocytopenic purpura, primary sclerosing cholangitis, and ulcerative colitis. More than $90 \%$ of patients with NMO have also recurrent symptoms [1-3]. The diagnosis of NMO requires the presence of two absolute criteria, plus at least two or three supportive criteria. The absolute criteria are optic neuritis and acute myelitis. The supportive criteria are: brain MRI finding not meeting criteria for MS at disease onset, spinal cord MRI with contiguous T2-weighted signal abnormality extending over three or more vertebral segments indicating a relatively large lesion in the spinal cord, and a positive aquaporin- 4 antibody test. A case that fulfills the above criteria is $99 \%$ sensitive and $90 \%$ specific for the diagnosis of neuromyelitis optica [2]. CSF white cell counts (WBC) can be normal or mildly elevated in NMO (median 19 cells $/ \mu \mathrm{l}$, and $>100$ cells $/ \mu \mathrm{l}$ are possible during relapse in $35 \%$ of cases). An elevated CSF protein was observed in $50 \%$ of cases, and cytology often reveals lymphocytic, monocytic, neutrophilic, and eosinophilic cell types that are usually absent in MS. T2-weighted MRI that primarily involves the central gray matter of the spinal cord on axial sections is highly suggestive of NMO. NMO involves a longitudinally extensive cord lesion, often extending over three or more spinal cord segments. However, MS involves fewer than two spinal segments. The cervical cord is affected in $60 \%$ of cases, and lesions may extend into the medulla. At presentation, MRI of the brain may be normal in $55-84 \%$, and brain involvement may occur in up to $85 \%$ of patients' overtime $[2,4]$.

Our patient presented with recurrent bilateral optic neuritis of several years before the onset of transverse myelitis. The diagnosis of NMO was made based on the clinical findings of recurrent optic neuritis and first occurrence of transverse myelitis involving multiple segments (C3 to T12) of spinal cord on MRI. The brain MRI findings were also in favor of NMO than MS. Consistent with previous reports $[1,2]$, the CSF analysis also showed low white cell count and high protein content. In our patient, biomarkers like NMO-IgG, antinuclear antibody, anti-Smith antibody, and CSF oligoclonal bands could not be assessed for they were lacking in the country. In a previous report of NMO from Ethiopia, a 24-year-old woman from Southwest Ethiopia presented to a public hospital with progressive flaccid quadriparesis of 2 weeks and left optic neuritis of 1-week duration [5]. The other case report described a 27-year-old female with recurrent visual loss and progressive quadriplegia with suggestive MRI and visual evoked potential findings and positive aquaporin-4 antibody. In none of these reports was brainstem or oculomotor involvement reported [6].

Brainstem symptoms have been reported recently in NMO. A multicenter study involving 258 patients with NMO showed that brainstem signs were observed in $31.4 \%$ of the patients, with vomiting $(33.1 \%)$ being the most common sign followed by hiccups $(22.3 \%)$, oculomotor dysfunction $(19.8 \%)$, pruritus $(12.4 \%)$, hearing loss (2.5\%), facial palsy $(2.5 \%)$, vertigo or vestibular ataxia $(1.7 \%)$, trigeminal neuralgia (2.5\%), and other cranial nerve signs (3.3\%). Most of these symptoms were reversible, but oculomotor dysfunction was persistent [7].

Another retrospective case study that evaluated 50 NMO patients showed $30 \%$ had brainstem involvement. The patients also had variable manifestations like in the 


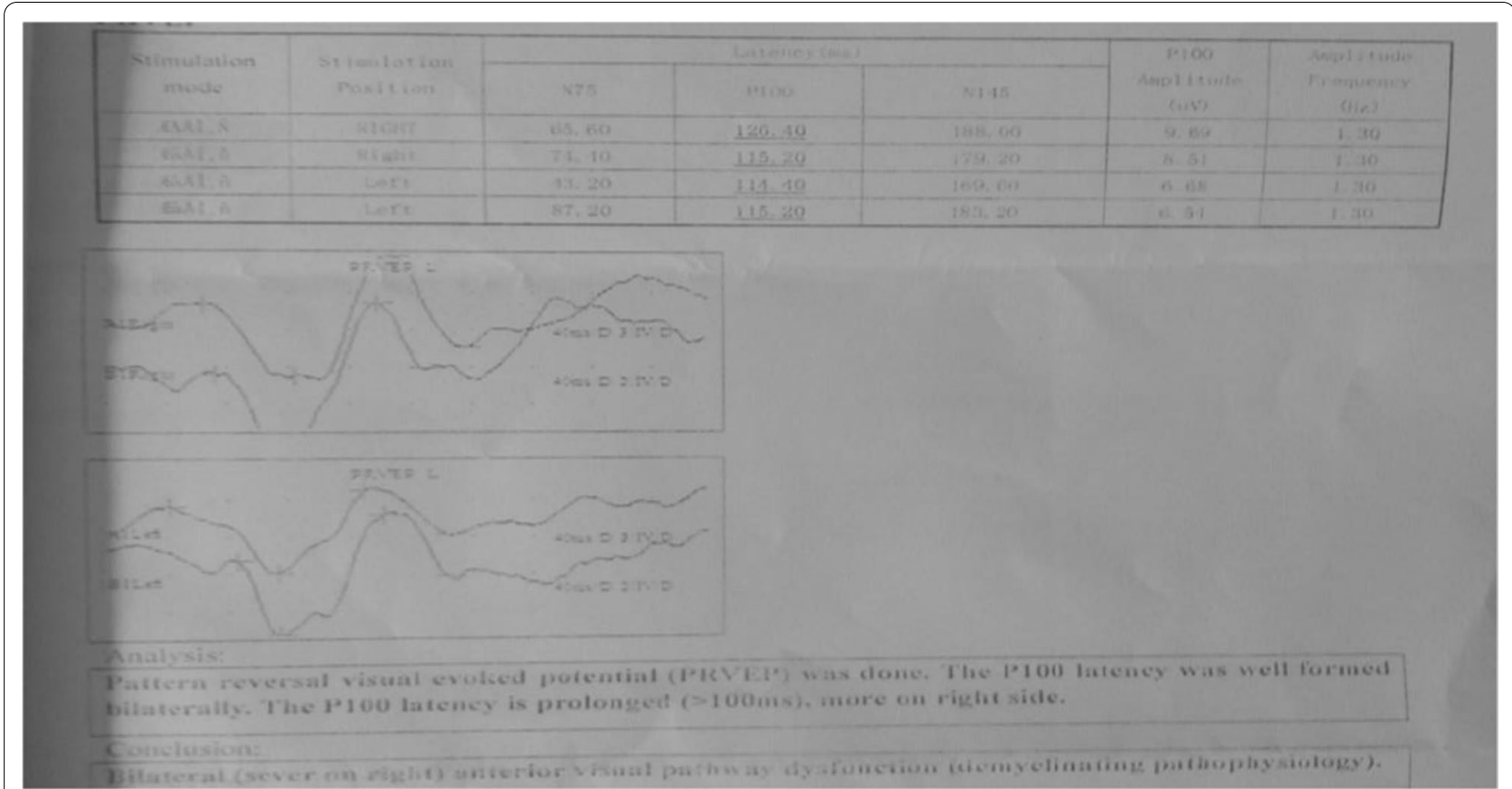

Fig. 2 Electrophysiology: pattern reversal visual evoked potential (PRVEP) revealing prolonged P100 latency (> 100 ms), more on the right side

previous study, including oculomotor dysfunction. The patient with oculomotor symptoms had lesions in the right cerebellar hemisphere and in the cerebral peduncle of the midbrain on brain MRI [8].

One of the most recent case reports published in 2019 showed a 61-year-old female who presented with an initial complaint of bilateral ptosis and diplopia without any motor or sensory symptoms. MRI showed mild lesions in the midbrain and third ventricle [9].

The main goals of treatment of NMO are to reverse symptoms and prevent future relapses. The treatment for acute attacks in a seropositive NMO is intravenous pulse methylprednisolone followed by oral prednisolone therapy, which will be tapered over several months after symptom resolution to prevent recurrence and complications. Patients who responded poorly to corticosteroid therapy are treated with intravenous immunoglobulin or plasmapheresis. NMO is associated with high relapse rate requiring maintenance immunosuppressive therapy with azathioprine and/or low-dose prednisolone. The treatment for seronegative NMO is similar to that of seropositive patients. In recent studies, rituximab was found to be an effective therapy for resistant or seronegative NMO patients. Patients who have frequent relapses during the first 2 years of follow-up, are severely sick at the initial attack, have late presentation, and have coexisting systemic lupus erythematosus or other autoimmune disorders were associated with poor prognosis [10].

\section{Conclusion}

It is prudent to suspect NMO in a patient with unexplained recurrent optic neuritis. NMO should be considered as a cause for bilateral oculomotor palsy. Early initiation of further diagnostic work-up and aggressive immunosuppressive treatment are essential to prevent recurrences and permanent neurologic disability. It is very important to follow patients with optic neuritis for a longer period.

\section{Abbreviations}

AQP4-Abs: Aquaporin-4 antibodies; AQP-4: Aquaporin-4; CSF: Cerebrospinal fluid; CNS: Central nervous system; FLAIR: Fluid-attenuated inversion recovery; HIV: Human immunodeficiency virus; IgG: Immunoglobulin G; MD: Medical doctor; MRI: Magnetic resonance imaging; MS: Multiple sclerosis; MRC: Medical Research Council; NMO: Neuromyelitis optica; PRVEP: Pattern reversal visual evoked potential; STIR: Short T1 inversion recovery; WBC: White blood cell count.

\section{Acknowledgements}

We would like to thank our patient for giving us consent to report her medical case. We are also grateful to the professional contribution of physicians and nurses of the St Paul's Hospital Millennium Medical College in the care of the patient.

\section{Patient's perspectives}

I feel very comfortable and healthy at this time with significant improvement of my symptoms. Additionally, my case is finally diagnosed after I have been treated in many hospitals. I like to thank my treating physicians for their work

\section{Authors' contributions}

$\mathrm{AM}, \mathrm{AK}$, and $\mathrm{SN}$ were involved in the collection, diagnosis, and management of this patient. AL and LT are senior ophthalmologists who evaluated the 
patient. RA, HF, HA, and SG did the literature search and prepared the manuscript. All authors read and approved the final manuscript.

\section{Funding}

Not applicable.

\section{Availability of supporting data}

Not applicable.

\section{Declarations}

Ethics approval and consent to participate

Not applicable.

\section{Consent for publication}

Written informed consent was obtained from the patient for publication of this case report and any accompanying images. A copy of the written consent is available for review by the Editor-in-Chief of this journal.

\section{Competing interests}

The authors declare that they have no competing interests.

\section{Author details}

'Department of Neuro-surgery, St. Paul's Hospital Millennium Medical College, Addis Ababa, Ethiopia. ${ }^{2}$ Department of Internal Medicine, St. Paul's Hospital Millennium Medical College, Addis Ababa, Ethiopia. ${ }^{3}$ Department of Gynecology, St. Paul's Hospital Millennium Medical College, Addis Ababa, Ethiopia. ${ }^{4}$ Department of Radiology, St. Paul's Hospital Millennium Medical College, Addis Ababa, Ethiopia. ${ }^{5}$ Department of Ophthalmology, St. Paul's Hospital Millennium Medical College, Addis Ababa, Ethiopia.

Received: 6 January 2021 Accepted: 20 July 2021

Published online: 01 October 2021

\section{References}

1. Wingerchuk DM, Lennon VA, Lucchinetti CF, Pittock SJ, Weinshenker BG. The spectrum of neuromyelitis optica. Lancet Neurol. 2007;6:805-15.
2. Etemadifar M, Nasr Z, Khalili B, Taherioun M, Vosoughi R. Epidemiology of neuromyelitis optica in the world: a systematic review and meta-analysis. Mult Scler Int. 2015;2015:174720.

3. Juryńczyk M, Craner M, Palace J. Overlapping CNS inflammatory diseases: differentiating features of $\mathrm{NMO}$ and MS. J Neurol Neurosurg Psychiatry. 2015;86:20-5.

4. Wingerchuk DM, Banwell B, Bennett JL, Cabre P, Carroll W, Chitnis T, et al. International consensus diagnostic criteria for neuromyelitis optica spectrum disorders. Neurology. 2015;85:177-89.

5. Jemal A, Bane A, Ali S. A 24-year-old female with neuromyelitis optica from Ethiopia. Ethiop Med J. 2017;55(4):320-3.

6. Heaton K, Shabana M, Gebreyohanns M. Diagnosis and treatment of neuromyelitis optica in Ethiopia. 2019;92(15 Supplement) P2.6-042.

7. Kremer L, Mealy M, Jacob A, Nakashima I, Cabre P, Bigi S, Paul F, Jarius S, Aktas O, Elsone L, Mutch K, Levy M, Takai Y, Collongues N, Banwell B, Fujihara K, de Seze J. Brainstem manifestations in neuromyelitis optica: a multicenter study of 258 patients. Mult Scler. 2014;20(7):843-7.

8. Jarius S, Kleiter I, Ruprecht K, Asgari N, Pitarokoili K, Borisow N, Hümmert MW, Trebst C, Pache F, Winkelmann A, Beume LA, Ringelstein M, Stich O, Aktas O, Korporal-Kuhnke M, Schwarz A, Lukas C, Haas J, Fechner K, Buttmann M, Bellmann-Strobl J, Zimmermann H, Brandt AU, Franciotta D, Schanda K, Paul F, Reindl M, Wildemann B, in cooperation with the Neuromyelitis Optica Study Group (NEMOS). MOG-lgG in NMO and related disorders: a multicenter study of 50 patients. Part 3: brainstem involvement-frequency, presentation and outcome. J Neuroinflamm. 2016;13(1):281.

9. Yasuda K, Maki T, Takata M, Kimura K, Takahashi T, Kanbayashi T, Murase N, Ohtani R, Takahashi R, Nakamura M. Bilateral oculomotor nerve palsy in a case of anti-aquaporin-4 antibody-positive neuromyelitis optica spectrum disorder. J Clin Neurosci. 2019;66:271-2.

10. Zéphir H, Bernard-Valnet R, Lebrun C, Outteryck O, Audoin B, Pittion S, Wierltewski S, Ouallet JC, Neau JP, Ciron J, Clavelou P, Mariginer R, Brassat D. Rituximab as first-line therapy in neuromyelitis optica: efficiency and tolerability. J Neurol. 2015;262:2329-35.

\section{Publisher's Note}

Springer Nature remains neutral with regard to jurisdictional claims in published maps and institutional affiliations.
Ready to submit your research? Choose BMC and benefit from:

- fast, convenient online submission

- thorough peer review by experienced researchers in your field

- rapid publication on acceptance

- support for research data, including large and complex data types

- gold Open Access which fosters wider collaboration and increased citations

- maximum visibility for your research: over $100 \mathrm{M}$ website views per year

At BMC, research is always in progress.

Learn more biomedcentral.com/submissions 